\title{
A relação mãe/criança com deficiência: sentimentos e experiências
}

\section{The relation mother/child with disabilities: feelings and experiences}

Atos Prinz Falkenbach ${ }^{1}$

Greice Drexsler ${ }^{1}$

Verônica Werler ${ }^{1}$
${ }^{1}$ Departamento deEducação Física, UNIVATES. Rua Avelino Tallini 171 Universitário. 95900-000 Lajeado RS. 155atos@univates.br
Abstract The present study aims at investigating the feelings and experiences of parents of children with disabilities. It was motivated by the idea of understanding the daily life of the parents of children that take part in the Relational Psychomotricity Project at U NIVATES. The protagonists of the study are the parents integrated in the project. The instruments used for data collection in this ethnographic qualitative study were interviews, field reports and analysis of documents. The study approached the following theoretical aspects: the primary relation, the medical relation and the social relation of the child with disability. The information is organized into the following categories, a) the feelings of the parents on occasion of the birth of a child with disability, b) the behavior of the medical staff when telling the fact to the parents, c) the needs of the parents in regard to their relations with their relatives and society, d) the feelings and needs with respect to educating a child with disability. The article concludes that the parents of children with disability re-evaluate their initial concepts, learn to value the potentialities of the child and require continuing reinforcement of their self-esteem for helping them in the educational process of their children.

Key words Education, Special, Family relations, Family health
Resumo 0 presente estudo investiga os sentimentos e as experiências de pais e mães de crianças com deficiência. Surgedas motivações em compreender o cotidiano dos pais e mães de crianças com deficiência integrante do Projeto de Psicomotricidade Relacional da U NIVATES. De corte qualitativo, trata-se de um estudo etnográfico. $0 \mathrm{~s}$ instrumentos utilizados para a coleta de informações são: entrevi stas, diários de campo eanálise documental. A temática aborda os seguintes aspectos teóricos: a relação primária, a relação do profissional da saúdee a relação social da criança com necessidades especiais. 0 processo de coleta de informações permitiu organizar as seguintes categorias: a) sentimentos manifestos no nascimento de um filho com deficiência; b) comportamento dos profissionais da área da saúde no ato de dar a notícia aos pais; c) necessidades dos pais e mães na relação com os demais familiares e a sociedade e sentimentos e e) necessidades envolvidas na perspectiva de educar uma criança com deficiência. Conclui-se que os pais e mães das crianças com necessidades especiais reavaliam seus conceitos iniciais, aprendem a valorizar as potencialidades da criança e requisitam contínuos reforços em suas estimas pessoais que os auxiliam no processo educativo de seus filhos.

Palavras-chave Educação especial, Relação familiar, Saúde da Família 
Introdução

A literatura deaconselhamento ede aspectos biológicos acerca das síndromes e das deficiência são abrangentes. Porém, ficam algumas indagações quando se refereao fato deser pai e de ser mãe de uma criança com deficiência. Quesentimentos os pais e as mães geram ao nascimento de um filho com deficiência? Como recebem a notícia? Que preparação recebem para essa finalidade, ou como se comportam os profissionais da área da saúde nesse momento delicado do desenvolvimento humano? Q uenecessidades os pais e as mães percebem junto à relação na família e à sociedade? Como se comportam diante da perspectiva de educarem uma criança com deficiência?

0 presente estudo surge das motivações dos investigadores em compreender o cotidiano de mães e de pais de crianças com deficiência participantes do Projeto de Psicomotricidade Relacional da UNIVATES - Centro Universitário. Investiga os sentimentos eas experiências das mães e dos pais de crianças com deficiência. Diferente da pretensão de ser um guia de aconsel hamento ou de buscar caracterizações sobre as diversas deficiências, a investigação descreve e interpreta o fenômeno em sua realidade: apresenta os obstáculos, as dificuldades, as mazelas, bem como os êxitos, os sucessos e os sentimentos envolvidos no cotidiano da relação de ser pai e de ser mãe de criança com deficiência.

A temática estudada se apoiou em referenciais como W innicott ${ }^{1,2}$, M ahler $^{3}$, Spitz ${ }^{4}, M$ aturana et al. ${ }^{5}$ eVygotsky ${ }^{6}$, bem como em Falkenbach et al. ${ }^{7}$. Ao iniciar as reflexões acerca da temática relacional da mãe e do pai de crianças com deficiência, destacamos a relação primária ea necessidade dessas relações serem nutridas com bases afetivas e sociais para um saudável desenvolvimento. A relação primária é uma relação fusional, simbiótica entre a criança ea mãe, que acontece no início da infância, sentimento em que o filho percebe a mãe como parte de $\mathrm{si}^{3}$. M aturana et al. ${ }^{5}$ abordam o fundamento do amor na relação humana. Spitz ${ }^{4}$ trata da relação inicial mãee filho para formação da personalidade e da saúde. Ensina que da mesma forma que a mãe influencia o filho, também recebe sua influência. A privação ou ausência pode provocar doenças de carência afetiva. A relação primária é substancial e incomparável a toda e qualquer relação que venha se estabelecer. Repercute em todas as demais relações na vida infantil e adulta ${ }^{1,4}$.

Considerando as influências externas no processo de desenvolvimento do ser humano, tor- na-se relevanter refletir sobreo papel do profissional da saúde no parto de uma criança com deficiência, considerando o fator surpresa nesse momento. A literatura explica que assim como poucos profissionais sabem dar a notícia, poucos pais sabem recebê la ${ }^{8}$.

Quando a questão é o nascimento de uma criança com deficiência, a intensidade da situação envolve uma repercussão complexa e imprevisível no contexto familiar. A dificuldade com 0 impacto da notícia sempre deixa marcas profundas nos familiares, principalmente na mãe e no pai, personagens diretamente relacionados com a causa e ainda culpabilizados pela perda de uma criança sonhada, idealizada e planejada 9 .

É comum as famílias darem início a inúmeras fantasias sobre o fato do casal gerar uma criança com deficiência ${ }^{10}$. Podem começar a fantasiar a imagem que a sociedade produz de pessoas com deficiência, que pode ser de pessoas dependentes, apáticas e improdutivas. É importante reconhecer quetal fantasia não énada além do próprio produto do imaginário pessoal eque está relacionado ao modo de pensar do casal.

As descrições com fundamento nos autores contribui na tomada de consciência das bases da relação dos pais com o filho com deficiência. Entendemos que se trata de um aprendizado, fundamentalmentedeum aprendizado social, na convivência com o outro. É nessa perspectiva que o estudo é construído, no entendimento de que as relações entre as pessoas se inscrevem como as bases para o desenvolvimento humano ${ }^{7}$.

\section{Método}

Pela sua natureza hermenêutica, o presente estudo se ajusta às características do modelo qualitativo de investigação em saúde, uma etnografia ${ }^{11}$. 0 estudo optou pela descrição, análise e interpretação das narrativas do grupo de pais e mães decrianças com deficiência integrantes do projeto de psicomotricidade. N esta modalidade de estudo, não há a preocupação em quantificar as informações e sim aprofundar os relatos e descrições da realidade dos fatos sem a necessidade de elaborar um juízo de valor.

Durante o processo da coleta de informações, foram organizadas situações para o desenvolvimento de entrevistas semi-estruturadas com os participantes da pesquisa e que se disponibilizaram a conceder entrevista acerca da sua experiência pessoal de ser pai ou mãe de uma criança com deficiência. Dedicamos especial escuta às palavras 
e manifestações dos pais e das mães escolhidos para o desenvolvimento da pesquisa que resultou no presente artigo. Podemos afirmar que se tratou de um exercício simples, pois contamos com a disponibilidade de cinco mães e de um pai que tradicionalmente permanecem na sala de espera do projeto aguardando o retorno de seus filhos.

Tomando como base os estudos de Gómez et al..$^{12}$ que assinalam a necessidade de critérios na elegibilidade dos contextos e participantes em estudos qualitativos, podemos destacar que as escolhas dos pais e das mães participantes precisaram estar em acordo com alguns critérios, que são:

a) ser pai ou mãe de uma criança com deficiência integrante do projeto de psicomotricidade;

b) o pai e a mãe estarem de acordo com os propósitos de investigação do estudo;

c) o seu filho ou filha haver participado com freqüência regular ede no mínimo um ano completo no projeto;

Os pais e as mães integrantes da pesquisa demonstraram boa aceitação e disponibilidade para serem entrevistados, demonstrando vontade em participar e serem escutados, valorizados em suas narrativas pessoais.

Foram utilizados os seguintes instrumentos para a coleta das informações:

* entrevistas semi-estruturadas: com os pais eas mães das crianças com deficiência do projeto depsicomotricidade;

* diário de campo: descrições informais das falas no cotidiano da espera dos pais e das mães durante a prática do projeto

* análise documental: estudo dos documentos da criança como pareceres descritivos, exames e outros documentos que auxiliaram na compreensão histórica da vivên cia com a criança com deficiência.

0 processo de coleta de informações foi analisado a partir do procedimento de triangulação das informações que permitiu maior fidedignidade na análise e interpretação dos resultados ${ }^{13}$. 0 processo pesquisado permitiu o desenvolvimento das reflexões que seguem.

\section{Resultados}

A pesquisa possibilitou organizar categorias de análise com o conteúdo coletado no agrupamento das questões significativas das informações. As categorias de análise organizadas são: a) os sentimentos dos pais em relação à temática das deficiências antes de terem seus filhos; b) os sen- timentos e as experiências durante a gestação; c) o parto e os primeiros contatos com o bebê; d) 0 momento de dar ereceber a notícia; e) as primeiras experiências de cuidados com o bebê; f) a criança com a família.

Em relação à primeira categoria, que aborda os sentimentos dos pais sobre 0 tema das deficiências, vai relatar o delicado entendimento que as mães e o pai das crianças com deficiência faziam sobre o tema, antes de virem a ter seus fiIhos. Os relatos descrevem:

Conhecia pessoas com deficiência. De alguma forma, elas sempre me chamaram a atenção na sociedade. Até coloquei no relatório que eu dizia para a minha mãe que se tivesse uma criança assim, iria amar muito ela. (Entr. n² em 04/05/ 2005).

Primeiro vem o sonho de querer ser mãe, depois vem o sonho de engravidar, depois a gente sonha em ter um criança perfeita, nunca pensa na possi bilidade da criança vir com algum problema, não sei se é porque não tinha na família, a gente semprequer ver eles com saúde. (Entr. $n^{\circ} 6 \mathrm{em} 03$ ) 10/06).

Não queria saber sobre crianças com deficiências, não conseguia nem ol har para elas, era muito difícil de encarar, não queria tomar conhecimento acerca do assunto. Nunca passou pela minha cabeça ter uma criança com alguma síndrome. (Entr. $\left.n^{\circ} 1 \mathrm{em} 27 / 04 / 2005\right)$.

É reconhecido que as experiências, as oportunidades de aprendizagens, a cultura em que historicamente conviveram são responsáveis em provocar pensamentos e imagens de um conceito sobre as deficiências, cujo impacto do nascimento de um filho com deficiência acaba por proporcionar reavaliações nos conceitos iniciais.

Quando falamos da relação dos pais com o filho, é importante considerar também o período prénatal, compreendido entre a concepção e 0 nascimento, a fase intra-uterina. Assim descrevemos os sentimentos relatados durante a gestação.

$N$ ão tomava nem uma aspirina, porquea gente lia sobre a talidomida, que as mulheres tomavam para azia eas crianças nasciam sem braços ou pernas. Tinha esta preocupação. 0 médico em uma consulta receitou-me ferro, vitaminas, e eu até perguntei senão tinha nenhum problema, ele disse que não. (Entr. n5 em 09/06/05).

Durante a gestação, sentia que havia algum problema, algo estava errado, mas meu marido dizia queeu estava ficando louca. Eu não podia falar o que sentia, que algo não estava certo, pois ficavam falando que era coisa da minha cabeça e não era para ficar chamando essas coisas. 0 médico só 
me informou que ia ser uma criança pequena. (Entr. ${ }^{\circ} 1 \mathrm{em} 27 / 04 / 2005$ ).

Nenhuma mãe deveria saber, no período da gestação, se a criança édeficiente, se não tem nada grave, que precisa interferir antes de nascer! Não precisa saber! Houve um erro na radiografia da minha filha e eu dei graças a Deus. Saber antes seria uma tortura, porque eu ia sofrer e ela ia sofrer no ventre sem nenhuma necessidade. Saber depois faz toda a diferença, porque depois há contato real, íntimo e de pele. 0 contato no ventre é subjetivo. (Entr. n² em 04/05/2005).

A criança sempre é uma fonte de ilusões ou de medos. A fantasia eas vivências que se produzem em torno da criança que está por vir são intensas, refletem uma projeção dos pais como também expectativas idealizadas ${ }^{14}$.

Passado o período de gestação, geralmente acompanhado de imaginação, sonhos e expectativas, finalmente é hora de ir ao encontro com a realidade, éhora de dar à luz e ver se concretizar o filho que foi imaginado. Essa categoria aborda o parto e os primeiros contatos com o bebê.

M ostraram-me ele bem enroladinho e colocaram um pouco do meu lado, mas logo tiraram alegando quetinham quelevar elepara aquecer. (Entr. $n^{\circ} 3 \mathrm{em} \mathrm{18/05/05).}$

Foi parto normal com analgesia, parto sem dor. Achei o parto bem tranqüilo, havia vários enfermeiros e estagiários ao redor por causa do tipo de parto, que na época, não era comum. Quando o menino nasceu, demorou um pouco para chorar, ele escorregou da mão do médico e arrebentou 0 cordão umbilical que era bem fino, sangrou muito. (Entr. n³ em 18/05/2005).

Eles colocaram a menina (síndrome de D own) ao meu lado, enquanto que a minha primeira fiIha, eles colocaram sobremim e eu pudetocar nela. Eles colocaram ela distante de mim, eu nem pude encostar. Q uando sabem que o recém-nascido tem síndrome deveriam aproximar da mãe, porque sabem que são estas crianças que precisam mais de nós. (Entr. n² em 04/05/2005).

0 parto consiste em crenças e práticas mutuamente dependentes e internamente consistentes, o que significa que este momento está intimamente ligado e se diferencia de acordo com a trajetória histórica e a influência de cada pessoa envolvida, médicos, enfermeiros, pacientes, acompanhantes ${ }^{15}$.

Passado o parto e os primeiros contatos com o bebê, vem o momento de dar a notícia. Não há dúvidas de que esse momento trata-se do episódio de maior sensibilidadena relação entreo profissional da saúdecom os pais. A adaptação pos- terior está intimamente relacionada com a capacidade de encontrar apoio, confiança e esclarecimentos reaisnas primeiras palavras sobre o ocorrido. 0 que significa que estamos diante de um momento decisivo.

Os relatos deincertezas e de desconforto com a notícia que os pais recebem é uma realidade. É como descrevem as mães entrevistadas:

0 médico logo chamou a pediatra, fiquei esperando que ele me desse os parabéns e me dissesse que era um belo de um guri. M as tudo o que pude ver foi urgência nos olhos do médico. 0 médico ficou frio comigo enão disse nada, parecia que ele estava frustrado por não ter percebido nada durantea gestação. (Entr. n³ em 18/05/2005).

Quando o médico informou a notícia, estava com minha prima. 0 médico esperou eu sair da sala e disse para ela que essas crianças não duravam muito, que no máximo duraria até os três anos. A minha prima disse para o médico que ela não daria essa notícia, que ele teria que me falar. (Entr. n¹ em 27/04/2005).

Durante seis meses da vida de minha pequena filha levei ela ao médico e ela estava sempre dormindo. N estedia da consulta, ela chorou e o médico me disse que ela poderia ter a síndrome do Cri Du Chat, na hora eu fiquei muito braba, xinguei ele e mandei ele procurar defeito nos filhos dele. É uma caminhada difícil até saber o resultado do carióti po. N este momento, a sensação foi que despenquei do oitavo andar, não ouvi mais nada eu caminhava sem chão, depois daquilo fiquei paralisada. A té as minhas férias foram anteci padas porquenão atinava mais nada no meu serviço. (Entr. $\left.\mathrm{n}^{\circ} 1 \mathrm{em} 27 / 04 / 2005\right)$.

Quando ocorre a surpresa do nascimento de uma criança com deficiência, há um choque intenso nos pais, mas que pode ser atenuado com a forma como a família se organiza com um suporte necessário para absorver da melhor forma possível. Em um mundo de comportamentos pragmáticos, de rendimento e de produção, a idéia que perpassa é a de uma criança que irá ser passada para trás, que irá sofrer, que não poderá desenvolver comportamentos de autonomia ${ }^{14}$.

Ao nascerem, os bebês se deparam com um mundo cheio de concepções e se el es tiverem alguma deficiência, podem enfrentar preconceitos e situações difíceis em suas relações. Assim os pais desenvolvem uma preocupação que os afeta de forma intensa após o nascimento. A categoria que segueaborda al gumas experiências de cuidados com o bebê.

Com a notícia que a criança tinha síndrome, tratamos defazer uma festa deum ano bem grande, 
pois estávamos esperando a qualquer momento a sua morte. Procuramosfazer detudo. Depoisquando comecei a levar a menina no fisioterapeuta, a minha outra filha ia junto e às vezes levava sua irmã, na época tinha dez anos eme dizia queia ser igual àquele médico, hoje ela esta cursando fisi oterapia e a fisioterapeuta que ela admirava é sua professora. (Entr. $n^{\circ} 1 \mathrm{em} 27 / 04 / 05$ ).

Estes primeiros anos foram difíceis porque ela teve que ser internada várias vezes, por conseqüência do problema cardíaco. Foi complicado, começava a dar febre e aí já era certo que a gente tinha que levar para o hospital de clínicas porque aqui na cidade eles não iam acertar o problema dela, não tinha como. N ormalmente ela ia para a UTI pediátrica. Ficava bem difícil, porque a mãe ficava lá e eu vinha trabalhar, e a menina quase em coma, aí eu tinha que ir correndo, aí quem corria o risco era eu. Teve uma ocasião em que eu estava levando a menina e deu uma convulsão nela antes de chegar, parei e entreguei ela para uma viatura da polícia rodoviária, a mãe foi junto e eu fui atrás. Eu não sabia qual era o hospital mais próximo, desta vez, ela quase morreu. (Entr. $n^{\circ} 4$ em 24/05/06).

As primeiras informaç̧ões que tive acesso vie ram da APAE efui buscar o curso de pós-graduação em psicomotricidade. Sempre fui atrás de livros. Entendo que a melhor maneira de poder ajudar é compreenden do sobre as capacidades de minha filha. (Entr. $n{ }^{\circ} 5$ em 09/06/2005).

A idéia inicial de que os pais empreenderiam uma dedicação mais intensa nos primeiros anos de vida e que depois os filhos seguem com autonomia e sustentabilidade passa a ser questionada eaté derrubada. A idéia de um cuidado constante e continuado é realidade em inúmeros $\operatorname{casos}^{14}$.

Quando a maré é mansa, qualquer barco navega com tranqüilidade, porém quando há maré revolta então apenas barcos estruturados conseguem manter a navegação em equilíbrio. Seguem os relatos dos entrevistados sobre suas experiências familiares.

A família foi espetacular, porque primeiro tivemos que comprar os aparelhos auditivos, eles são caros. Nós sempre tivemos ajuda da família, pois tudo era particular, a fonoaudióloga, as viagens. (Entr. n6 em 03/10/06).

Diantedenós a família agiu normalmente, talvez por trás choraram um pouco, mas hoje não aparece preconceito visível, ela tem limitações, talvez eles não falam para não incomodar a gente. (Entr. n4 em 24/05/05).

Sofro quando acontece algum tipo de preconceito, pois eu não posso estar sempre com ele para defendê $\mid 0$. A todo instantemepego pensando como estarão tratando-o na escola, como as outras pessoas o ajudam ou zombam dele, e isso acaba me deixando muito preocupada e sofrida. Preconceito a família não tem, só querem cuidar muito dele, pois ele é o único com síndrome na família, eles não sabem muito sobrea síndromedeD own. (Entr. $n^{\circ} 3 \mathrm{em} \mathrm{18/05/2005).}$

Independentemente da abrangência da busca de informações, muitas perguntas sobre as perspectivas futuras das crianças e de como a família enfrentaráa situação podem permanecer sem respostas. Os pais necessitam de recursos profissionais confiáveis e atualizados sobre crianças com deficiência, para que possam recorrer conforme surjam questões ou preocupações especiais.

\section{Discussão}

Ver, ouvir, falar e estudar sobre o tema das deficiências pode proporcionar bons conhecimentos, porém a vivência e a convivência com estas pessoas é o que pode proporcionar aprendizagens profundas e novos olhares. É comum o entendimento de que o preconceito existente com as pessoas com deficiências é fruto de um processo histórico e cultural presentena maioria das pessoas até algumas décadas atrás. As entrevistas realizadas com os pais participantes do estudo apresentam relatos dos sentimentos e das relações estabelecidas com as pessoas com deficiências antes da realidade de conviver com um filho com deficiência.

Também podemos refletir a hipótese de que quando há algum conhecimento, acaba-se por negá-lo, ou seja, é feito de conta que não existe. Em síntese, o pensamento comum éo dequenão há possibilidade de vir a ter, em qualquer tempo e espaço, que conviver com uma pessoa com deficiência. A cultura de negação é superior a qualquer possibilidade, assim o sofrimento é agudo naqueles que convivem com essa experiência.

Sem surpresas, deparamo-nos com alguns relatos dos pais entrevistados que demonstraram respostas com restritas informações sobre as deficiências antes da experiência com seus fiIhos. Também são significativos os relatos de reconhecimento dos comportamentos de preconceito, de medo e de superstições sobre as pessoas com deficiências antes que tivessem seus filhos.

Percebe-se nos relatos que há distâncias das informações ou interesse em saber sobre 0 assunto das deficiências, quando não possuem casos na família. Estas podem vir a fazer julgamen- 
tos precipitados sobre 0 assunto. A falta de informações e o preconceito podem fazer o processo de aceitação da criança pelos seus pais ser doloroso, justamente por não saber a respeito da deficiência que a criança possui. Afinal, ela estará aprendendo com a convivência no ato de ser mãe de uma criança com deficiência.

0 fato interessante evidenciado na pesquisa trata-se da relação estabelecida entre as impressões e os sentimentos antes do filho com deficiência e o processo de aceitação. Segundo os relatos, para as mães que tiveram pouco contato e informação sobre o assunto, o processo de aceitação demonstrou ser mais lento e doloroso, enquanto que o processo era facilitado para aque les que tiveram maior convivência.

É reconhecido que desde o momento em que se descobre a gravidez, pais e mães começam a fazer planos quanto ao futuro do filho. Dificilmente pensam na possibilidade de vir a ter um bebê com deficiência. A gravidez geralmente é acompanhada de comemoração e de expectativas. Os familiares e conhecidos esperam ansiosamente o momento do nascimento da criança e compartilham do planejamento sobre sua chegada. Qualquer eventualidade desconhecida ou não planejada pode ser uma realidade dura para ser assimilada.

O período de gestação também éde dúvidas, receios e, principalmente quando se trata do primeiro filho, essas dúvidas que envolvem o universo da mãe parecem ser pouco creditadas e reconhecidas. Os sentimentos, medos, receios são pouco creditados pelas pessoas que convivem com as mães, inclusive familiares e médicos.

As mães participantes do estudo foram unânimes ao dizer que aceitaram a gravidez imediatamente após sua confirmação. Independentemente de terem planejado ou não a gravidez ou terem outros filhos, todas as mães entrevistadas relataram sentimentos de felicidade ao saber da gravidez. A literatura explica que, ao tomar conhecimento da gravidez, a mulher pode ter sentimentos variados quanto a sua nova condição, desde mudanças em seus padrões familiares até questões como problemas econômicos, interpessoais e intrapessoais que poderão influenciar no desenvolvimento do bebê.

No entanto, passado os primeiros meses de euforia, mesmo aquelas mães, participantes da pesquisa, cujas condições favorecem o desenvolvimento sadio da gravidez, relataram algumas passagens em que sentiram receios e preocupações. A sensibilidade materna sempreéum fenômeno a ser reconhecido econsiderado. É interes- sante verificar como a palavra de um profissional da saúde acaba por repercutir na orientação das mães. N ovamente, há negação sobre a possibilidade de haver uma gestação de uma criança com deficiência. A cultura educa para sequer pensar sobre uma hipótese, pois isso estaria atraindo realidades não desejáveis.

Outra discussão durante o período de gestação éa realização de exames que possam dizer se há alguma deficiência com o bebê, ainda antes do nascimento. 0 que seria o mais correto, ou menos doloroso, contar antes, durante o período gestacional, para tranqüilizar a mãe e preparar para receber a criança? O u não realizar o examepara não interferir na relação inicial da mãee da criança? N esse estudo, as mães entrevistadas declaram preferir não saber que seu filho possui deficiência durante a gestação, por receio de afetar o feto com algum sentimento negativo.

0 estudo narra as manifestações de cinco mães e de um pai das crianças sem entrar no mérito de que seja certo ou errado, mas principalmente para apresentar experiências com essa realidade. Para alguns, poder saber da notícia antes poderia ser positivo, iniciaria o processo de aceitação da criança. Essa decisão certamente é de cada uma e deve ser respeitada e compreendida em acordo com as circunstâncias da realidade de cada família.

0 importante neste momento é entender 0 quanto a mãe precisa ser bem atendida e compreendida pelas pessoas que estão a sua volta. 0 simples fato de escutá-la, de realizar os exames médicos que solicita parece ser de grande valia, conforto e ajuda para a mãe. Essas pequenas providências constituem-se em suas necessidades imediatas e ajudam a evitar a apreensão de angústias, medos e traumas, proporcionando uma gravidez tranqüila e sadia, em termos psicológicos, tanto para a mãe como para o bebê, ajudando na consolidação de um processo relacional positivo que levarão consigo para o resto de suas vidas.

Em relação ao parto e os primeiros contatos com o bebê, podemos refletir: haverá diferença na relação da mãe com o filho no momento do nascimento? Como serão os contatos, as aproximações seguintes entre a mãe e a criança?

M ais do que questões biológicas e científicas da medicina, o parto envolve questões culturais, sociais, crenças, superstições, higiene, religiosidade, entre outros, promovidas de um sistema cultural abrangente. Cada pessoa presente e envolvida nesse ato acompanha-o e compartilha suas experiências prévias, que são sempre muito 
intensas. $\mathrm{Na}$ cultura ocidental, prevalece 0 sistema dos profissionais médicos, um conjunto padronizado de práticas obstétricas ${ }^{16}$.

Desejar abraçar, beijar, fazer carícias, sorrir, conversar e manipular o seu bebê são as primeiras experiências táteis das mães para com seu filho. A relação afetiva entre a mãe e a criança educa aúltima para compreender quea peleéum fundamental órgão sensorial eque as experiências táteis vividas na relação primária são cruciais para o desenvolvimento saudável da criança.

As mães entrevistadas relatam uma experiência tátil diferente com seus filhos com deficiência nos momentos seguintes ao parto, devido também ao comportamento demonstrado por parte dos profissionais da saúde. Tal comportamento desperta interesse, pois uma criança quenasce com saúde é festejada e entregue à mãe com satisfação e quando há suspeita de que a criança tenha deficiência, ela é deixada ao lado da mãe. Em conversa com a mãe, ela pôde nos relatar quehavia percebido no médico um receio em Ihe entregar a criança. Foi muito diferente do momento do parto com a primeira filha. Parecia que o médico estava constrangido com o fato da criança haver nascido com síndrome de Down.

Ao descobrir que o filho idealizado possui alguma limitação que o diferencia dos padrões convencionais, podem surgir sentimentos como culpas, angústias, medos e perda do filho idealizado $^{8,9,14}$. Tal circunstância pode ser agravada na relação com o profissional da saúde.

0 ponto principal que se quer destacar é a característica humanizadora que deve envolver todo o processo da maternidade. A saúdee desenvolvimento de ambos podem ser favorecidos pelo ambiente, inclusive no hospital, lugar onde também se constrói boa parte das relações iniciais e onde os profissionais envolvidos devem estar atentos não somente às necessidades físicas da mãe, mas também as suas necessidades relacionais.

0 momento de dar e receber a notícia que a criança possui al guma deficiência pode ser crucial na vida do bebê e de sua mãe, pois dependendo da forma que a notícia for abordada poderá trazer dificuldades no relacionamento da mãe com seu bebê. 0 olhar da mãe para o seu filho reflete como espelho, desnuda as sensações e emoções que ela sente e que transmite ao bebê․

Não sepode escolher um filho segundo crité rios de "perfeição". Ao receber o diagnóstico de uma criança com deficiência, começam a aparecer apreensões e preocupações quanto ao desenvolvimento e procedimentos a serem tomados. As reações dos pais e das mães no momento do resultado do exame pode ser um momento muito confuso, cheio de dúvidas edeincertezas quanto ao seu futuro e o do filho.

As mães entrevistadas relatam que sentem como sefosse para si toda a depreciação queocorrecom o seu filho. Portanto a mãe precisa travar uma luta contra as dificuldades que acometem com seu filho que não deixa de ser uma luta por si mesma?.

As reações dos médicos podem ser as mais diversas. $N$ as entrevistas, percebemos queos pais estão atentos se algo estranho está acontecendo. Eles percebem na forma do profissional da saúde agir que algo não está normal, especialmente para os pais que já tiveram a experiência com outros filhos.

Quando um profissional da saúde, geralmente o médico, tem alguma suspeita ou certeza, é natural que chegue a difícil hora de comunicar a família, mas essa pode ser bastante melhorada quando ele dispõe de bons conhecimentos sobre as síndromes.

A mãe juntamente com a família pode proporcionar desenvolvimento de seu filho em todos os aspectos: físico, afetivo, social e intelectual. 0 diagnóstico rápido permite aproveitar uma característica do cérebro que é chamada plasticidade neural. Por esse mecanismo, a função de uma área lesada do cérebro pode ser assumida por uma área vizinha, quando a criança receber estímulo e trabalhos adequados ${ }^{17}$. Enfrentar a realidade, aceitar os fatos que podem trazer dor e sofrimento, ajuda em experimentar sentimentos puros como o amor, compreensão e ternura. Refletido o momento que a mãe recebea notícia do médico, podemos passar a pensar sobre a integração dessa criança com a sua família.

A primeiras experiência dos pais com uma criança ésempreúnica. Um pai ou uma mãe possui comportamentos diferentes no processo educativo de cada um de seus filhos². O pai ou a mãe que educa o segundo filho já não éo mesmo que foi durante a educação da primeira criança. Se o pai ea mãe possuem oito filhos, eles foram também um pai e uma mãe diferente para cada um desses oito filhos. Não podia ser diferente, pois há um profundo aprendizado na experiência de ser pai e deser mãeque vai aprimorando, modificando a cada filho queé educado. 0 contrário a isso seria pensar que o pai e a mãe são como robôs e possuem uma programação exata para cumprir com seus diferentes filhos em suas diferentes circunstâncias, tempos e espaços.

Sobreas primeiras experiências das mães com os filhos com deficiência, destacamos o fato de 
que é possível perceber que as pessoas não estão preparadas para gerar crianças com deficiência e que essa possi bilidade sequer passa em seus pensamentos.

Depois do nascimento do filho, as mães começam a se interessar e buscar informações sobreas deficiências. Seus conceitos semodificam e fazem com que elas passem a olhar com outros olhos a deficiência. $N$ as entrevistas, as mães relatam que estão em contínuo esforço em busca de informações para melhor atender os seus filhos.

As entrevistas realizadas oportunizaram a compreensão de que há um contínuo esforço de aprender e de obter cada vez melhores esclarecimentos para agir de forma adequada e com a convicção de estarem fazendo o melhor possível para suas crianças. M esmo que para isso seja necessário buscar cursos, leituras e até mesmo qualificação acadêmica para avançar nessa área.

Os sentimentos de dúvidas e de dificuldades eram freqüentementerevelados nos testemunhos dosentrevistados. Podemos reconhecer com tranqüilidadequea incerteza foi sentimento constante manifesto nas entrevistas realizadas, quando se trata das primeiras experiências no papel de ser mãe e de ser pai de uma criança com deficiência.

Quando ocorre a surpresa de um nascimento de uma criança com deficiência, há um choque intenso nos pais, mas que podeser atenuado com a forma como a família se organiza com um suporte necessário para absorver esse impacto da melhor forma possível ${ }^{14}$. Em um mundo de comportamentos pragmáticos, de rendimento e de produção, a i déia que perpassa éa de uma criança que irá ser passada para trás, que irá sofrer, quenão poderá desenvolver comportamentos de autonomia. Assim os pais desenvolvem uma preocupação que os afeta de forma intensa após 0 nascimento. 0 tópico quesegue aborda um pouco da convivência na família.

A família éo primeiro etalvez o principal grupo social em que convivemos, é nela que aprendemos a conquistar a individualidade eindependência ${ }^{4}$. Os desafios surgirão para a família que superou ou não as dificuldades iniciais. M as fica claro que a família que melhor busca apoio entre si ebusca formas de amparo e de suporte éaquela que também pode tolerar e suportar situações que perseveram dificultosas.

Durante as entrevistas, ficaram evidentes as necessidades de estima e de confiança que poderiam ser reforçadas também pela equipe médica. Os relatos sobre a deficiência dos profissionais da saúde em estimar e valorizar os pais estão muito aquém do que Gutfreind ${ }^{18}$ considera rele- vante para uma boa saúde familiar. Para o autor, a família precisa ser valorizada, pois somente assim é possível transmitir sua estima e confiança para a criança que necessita desse suporte dos pais. Como os pais fragilizados em razão de uma relação destruidora de suas estimas por alguns profissionais da saúde poderiam estimar e valorizar seus filhos, quando eles são desacreditados e desvalorizados?

Diantedo fato do nascimento deum filho com deficiência, é possível que os pais possam ceder espaços que os influenciam para conceber a imagem quea sociedade produz de pessoas com deficiência, como pessoas dependentes, apáticas e improdutivas. Geralmente essa imagem faz com que a criança obtenha dificuldades em seu processo de aceitação pela família, com conceitos negativos que prejudicam na integração social e no processo de aprendizagem e desenvolvimento ${ }^{10}$.

É certo ecompreensível quea tar efa de ser pai ou mãenão é fácil, porém percebe-senos relatos queégratificanteprincipalmentequando seconsegue perceber os pequenos avanços de seu filho. Alguns avanços considerados mínimos, que passam imperceptíveis nas experiências dos pais com filhos anteriores, são grandes vitórias e muito valorizados nessa nova relação ${ }^{14}$.

A interação com o filho éum relacionamento de mão-dupla, no qual os participantes se relacionam e se modificam mutuamente. Todos dão, recebem e se transformam, crescem e amadurecem. A pesar de todas as frustrações e dificuldades, criar um filho com deficiência pode tornarseuma das experiências mais enriquecedoras que alguém pode ter. É como explica Gutfreind ${ }^{18}$ : 0 que é uma cura senão abrir mão de uma idealização e aceitar a sua vida, evidente que sem renunciar de lutar por todas as possibilidades de avanços e de felicidades.

\section{Conclusão}

0 processo de coleta de informações possibilitou compreender como os pais e as mães tornaramse compreensivos e sensibilizados com a questão das deficiências, cujo conceito anterior sobre 0 fenômeno era de desprezo ede desconhecimento. Passaram a ser atuantes em atividades relacionadas ao processo educativo de seus filhos e também de demais crianças com deficiência.

Outro aspecto destacado no estudo trata da relação com os profissionais da área da saúde. 0 processo de coleta de informações, as entrevistas realizadas enfatizam a necessidade de aprimora- 
mento da área da saúde para a notícia e para o primeiro contato da família com a criança. 0 relato dos pais e das mães é de que os profissionais da saúde não estavam preparados para Ihes ajudar e nem orientar.

Pudemos compreender que os sentimentose as reações ocorrem por serem experiências inéditas dentro de uma família. A superação da ansiedade, da dor e sentimentos negativos precisa do apoio conjunto da família, bem como de uma estrutura a ser construída frente às dificuldades que surgirão. 0 processo de inclusão social tanto na escola como no trabalho e a temeridade frente a esses desafios são manifestados pelos protagonistas do estudo.

Compreendemos que os pais e as mães de crianças com deficiência reavaliam seus conceitos iniciais acerca das deficiências, aprendem a valorizar as potencialidades da criança e requisitam contínuos reforços em suas estimas pessoais que os auxiliam no processo educativo de seus filhos.

\section{Colaboradores}

AP Falkenbach trabalhou na orientação metodológica e teórica, redação e revisão final do texto. G Drexsler, na análise da pesquisa, estruturação do artigo e redação do texto. $V$ Werler trabaIhou na coleta de dados da pesquisa, metodologia, análise e interpretação de dados.

\section{Referências}

1. Winnicott DW. A criança e seu mundo. 4a ed. Rio de Janeiro: Guanabara Koogan; 1982.

2. Winnicott DW. Os bebês e suas mães. São Paulo: Martins Fontes; 1999.

3. Mahler MS, Pine F, Bergman A. O nascimento psicológico da criança: simbiose e individuação. Porto Alegre: Artes M édicas; 1993.

4. Spitz R. 0 primeiro ano de vida. São Paulo: Martins Fontes; 2000.

5. Maturana $\mathrm{H}$, Verden-Zöller $\mathrm{G}$. Amar e brincar: fundamentos esquecidos do humano do patriarcado à democracia. São Paulo: Palas Athenas; 2004.

6. Vygotsky LS. A formação social da mente. São Paulo: Martins Fontes; 2000.

7. Falkenbach AP, Drexsler G, Werler V. A relação mãe/ criança com necessidades especiais. Lajeado: UNIVATES; 2007.

8. Pupo Filho RA. O momento da descoberta. In: Souza AM C, organizador. A criança especial: temas médicos, educativos e sociais. São Paulo: Roca; 2003. p.1-5.

9. M annoni M. A criança retardada e a mãe. São Paulo: Martins Fontes; 1999.

10. Nicolosa A, Freitas NS. O compromisso da família na formação autônoma do deficiente mental. Cadernos de Educação Especial 1997; 1(9):66-70.

11. Pope C, Mays N. Pesquisa qualitativa: na atenção à saúde. Porto Alegre: Artmed; 2005.

12. Gomés GR, Flores JG, Jiménez EG. M etodología de la investigación cualitativa. Granada: Aljibe; 1996.

13. Triviños ANS. Introdução à pesquisa em ciências sociais: a pesquisa qualitativa em educação. São Paulo: Atlas; 1995.

14. Paniagua G. A família de crianças com necessidades educativas especiais.In: Souza AM C, organizador. A criança especial: temas médicos, educativos e sociais. São Paulo: Roca; 2003. p. 330-346.

15. M ontagu A. Tocar: 0 significado humano da pele. São Paulo: Summus; 1988.

16. Klaus MH, Kennel J. Pais/bebês: a formação do apego. Porto Alegre: Artes Médicas; 1992.

17. Pupo Filho RA. Interagindo com a criança especial. In: Souza AM C, organizador. A criança especial: temas médicos, educativos e sociais. São Paulo: Roca; 2003. p.6-14.

18. Gutfreind C. Vida e arte: a expressão humana na saúde mental. São Paulo: Casa do Psicólogo; 2005.

Artigo apresentado em 12/07/2006

A provado em 27/06/2007

Versão final apresentada em 10/07/2007 